J. Lake Sci. (湖泊科学), $2006, \mathbf{1 8}(3): 238-242$

http:// www. jlakes. org. E-mail: jlakes@ niglas. ac. cn

(c) 2006 by Journal of Lake Sciences

\title{
江苏新沂河河漫滩表面流人工湿地对污染河水的净化试验"
}

\author{
吴建强 ${ }^{1}$, 黄沈发 ${ }^{1}$, 阮晓红 ${ }^{2}, 丁$ 玲 $^{2}$ \\ ( 1 : 上海市环境科学研究院, 上海 200233$)$ \\ ( 2 : 河海大学环境科学与工程学院,南京 210098$)$
}

摘 要: 通过构建于新沂河河漫滩上的表面流人工湿地系统处理污染河水的现场中试研究表明, 在 $\mathrm{COD}_{\mathrm{Mn}}$ 和 $\mathrm{NH}_{4}^{+}-\mathrm{N}$ 进 水浓度分别为 $11.69-60.00 \mathrm{mg} / \mathrm{L}$ 和 $1.37-20.18 \mathrm{mg} / \mathrm{L}$ 时, 种植千屈菜、美人蕉、香蒲、水葱 4 种不同植物的表面流人工 湿地系统, 对 $\mathrm{COD}_{\mathrm{Mn}}$ 的平均去除效率分别为 $26.44 \% 、 40.12 \% 、 46.71 \% 、 28.23 \%$, 对 $\mathrm{NH}_{4}^{+}-\mathrm{N}$ 的平均去除效率分别为 $64.27 \% 、 70.49 \% 、 66.78 \% 、 58.52 \%$, 其中香蒲和美人蕉的净化能力较强. 4 种植物中水葱的耐淹能力最强, 在完全淹水 达 $22 \mathrm{~d}$ 以上时, 水葱依然生长良好; 千屈菜的耐淹能力最弱, 在完全淹水 $7 \mathrm{~d}$ 后就开始枯菱, 淹水 $17 \mathrm{~d}$ 后地上、地下部分全 部死亡.

关键词:表面流人工湿地系统;污染河水;水生植物;耐淹性能

\section{Treatment of polluted river water using surface flow constructed wetlands in Xinyi River Floodplain, Jiangsu Province}

\author{
WU Jianqiang ${ }^{1}$, HUANG Shenfa ${ }^{1}$, RUAN Xiaohong ${ }^{2} \&$ DING Ling ${ }^{2}$ \\ (1: Shanghai Academy of Environmental Science, Shanghai 200233 ,P. R. China); \\ (2:College of Environment Science and Engineering, Hohai University, Nanjing 210098, P. R. China)
}

\begin{abstract}
Treatment of polluted river water with variations of water quality using pilot-scale Surface Flow Constructed Wetland (SFCW) in Xinyi River Floodplain, Jiangsu Province was studied in this paper. The main results show that: When the influent concentrations of $\mathrm{COD}_{\mathrm{Mn}}$ and $\mathrm{NH}_{4}^{+}-\mathrm{N}$ were $11.69-60.00 \mathrm{mg} / \mathrm{L}$ and $1.37-20.18 \mathrm{mg} / \mathrm{L}$, the $\mathrm{COD}_{\mathrm{Mn}}$ and $\mathrm{NH}_{4}^{+}-\mathrm{N}$ removal rate of SFW which planted Lythrum salicaria, Canna indica, Typha latifolia and Scirpus locustris were $26.44 \%, 40.12 \%, 46.71 \%, 28.23 \%$ and $64.27 \%, 70.49 \%, 66.78 \%, 58.52 \%$, respecfioely. Typha latifolia and Canna indica have stronger ability for purifying pollutants. Scirpus locustris has the strongest ability of inundation, it can resist inundation of over 22 days and still live. Lythrum salicaria has the lowest ability of inundation, it only can resist inundation of 7 days.
\end{abstract}

Keywords: Surface Flow Constructed Wetlands; polluted river water; aquatic plants; ability of inundation

新沂河全长 $144 \mathrm{~km}$, 河床宽 $2500-2800 \mathrm{~m}$, 设计行洪流量 $6000 \mathrm{~m}^{3} / \mathrm{s}$, 但在一年的大部分时间里流量很 小, 仅通过南北偏泓下泄. 其中北偏泓作为污水专道, 承接来自于新沂市的全部工业废水、部分生活污水以 及山东莒县、莒南和临沭县的废水. 大量高浓度污水的下泄严重破坏了新沂河沿线及近海生态环境,给沿 岸居民的生活造成了严重危害. 为了治理新沂河污水专道内污水, 减轻或消除其对周围生态环境的影响, 水利部和江苏省相继提出采用生物 - 生态处置工程来研究治理新沂河污染河水.

本文通过对构建在新沂河滩地上的表面流人工湿地系统 (Surface Flow Constructed Wetland,SFW) 进行 的现场中试研究, 论证了利用表面流人工湿地处理新沂河污染河水的可行性, 分析了系统对污染河水的去 除效果, 比较了不同植物的净化能力和耐淹性能, 为类似河道建设生物 - 生态处置工程和植物选型提供了 借鉴依据. 


\section{1 材料与方法}

\section{1 工艺流程}

中试工程工艺流程如图 1 所示.

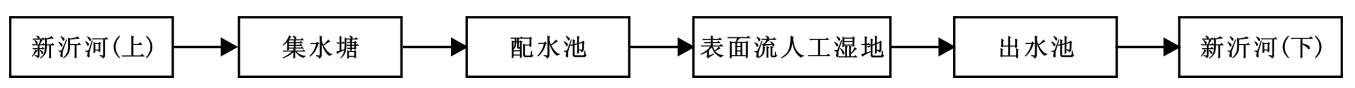

图 1 湿地系统中试工程工艺流程

Fig. 1 Flow chart of testing wetland system

\section{2 工艺设计}

(1) 人工湿地构造:4 块表面流人工湿地, 每块面积 $300 \mathrm{~m}^{2}(60 \mathrm{~m} \times 5 \mathrm{~m})$;

(2) 水力负荷: $0.1 \mathrm{~m} / \mathrm{d}$.

\section{3 植物选型及栽种}

由于中试工程处于行洪河道滩地,所选水生植物既要满足一般要求,还必须耐淹且不影响行洪. 综合 考虑, 选择 2 种土著植物: 香蒲 (Typha latifolia) 和美人蕉 (Canna indica), 另外, 还选择 2 种外来物种: 耐淹 性能极强的水葱 (Scirpus validus) 和极具观赏价值的千屈菜 (Lythrum salicaria). 芦苇由于植株高 (最高可达 $4.0 \mathrm{~m}$ 左右)、蔓延速度快, 会阻碍行洪而不予采用.

所选植物均于 2004 年 3 月下旬移栽, 种植密度为 6 棵 $/ \mathrm{m}^{2}$, 栽种后整个系统开始运行.

\section{4 监测方法}

新沂河污水主要超标因子为 $\mathrm{COD}_{\mathrm{Mn}}$ 和 $\mathrm{NH}_{4}^{+}-\mathrm{N}$ (据江苏省水环境监测中心淮阴分中心的监测结果,新沂 河河水中的 $\mathrm{NH}_{4}^{+}-\mathrm{N}$ 值占 $\mathrm{TN}$ 的 75\%-90\%, 故 $\mathrm{NH}_{4}^{+}-\mathrm{N}$ 的变化基本可以代表 $\mathrm{TN}$ 的变化), 因此,试验只对系 统进出水的 $\mathrm{COD}_{\mathrm{Mn}}$ 和 $\mathrm{NH}_{4}^{+}-\mathrm{N}$ 进行监测, 监测方法参照《水和废水监测分析方法》 ${ }^{[1]}$.

4 种水生植物均在栽种后 1 星期左右开始萌芽生长, 到 5 月份植物长势喜人,根系深人土壤. 5 月份开 始取样分析,每 $3 \mathrm{~d}$ 一次, 七月份行洪开始, 停止取样, 但继续观测行洪期间植物的生长状况.

\section{2 结果与讨论}

\section{$2.1 \mathrm{COD}_{\mathrm{Mn}}$ 的去除效果}

4 个不同植物的表面流人工湿地系统 $\mathrm{COD}_{\mathrm{Mn}}$ 的进出水浓度和平均去除效率如表 2,20 次监测结果及进 出水 $\mathrm{COD}_{\mathrm{Mn}}$ 浓度变化如图 2 .

表 1 表面流人工湿地系统试验 $\mathrm{COD}_{\mathrm{Mn}}$ 监测结果

Tab. 1 Monitoring results of $\mathrm{COD}_{\mathrm{Mn}}$ of SFW system

\begin{tabular}{|c|c|c|c|c|c|}
\hline \multirow{2}{*}{$\begin{array}{l}\text { 植物 } \\
\text { 类型 }\end{array}$} & \multicolumn{2}{|c|}{ 进水浓度 $(\mathrm{mg} / \mathrm{L})$} & \multicolumn{2}{|c|}{ 出水浓度 $(\mathrm{mg} / \mathrm{L})$} & \multirow{2}{*}{$\begin{array}{c}\text { 平均去除率 } \\
(\%)\end{array}$} \\
\hline & 范围 & 平均 & 范围） & 平均 & \\
\hline 千屈菜 & & & $7.86-48.91$ & 18.55 & 26.44 \\
\hline 美人蕉 & $11.69-60.00$ & 25.22 & $7.87-30.37$ & 15.10 & 40.12 \\
\hline 香蒲 & & & $7.19-24.16$ & 13.44 & 46.71 \\
\hline 水葱 & & & $8.54-46.14$ & 18.10 & 28.23 \\
\hline
\end{tabular}

表 2 数据显示, 进水浓度相同时, 香蒲系统出水 $\mathrm{COD}_{\mathrm{Mn}}$ 平均浓度最低, 仅为 $13.44 \mathrm{mg} / \mathrm{L}$, 达到《地表水环 境质量标准》( GB3838 - 2002) V 类水标准; 千屈菜系统出水 $\mathrm{COD}_{\mathrm{Mn}}$ 平均浓度最高, 为 $18.55 \mathrm{mg} / \mathrm{L} .4$ 个系统 对 $\mathrm{COD}_{\mathrm{Mn}}$ 的去除效果差别明显, 以平均去除率计, 香蒲和美人蕉系统超过 $40 \%$, 而千屈菜和水葱系统则低 于 $30 \%$. 


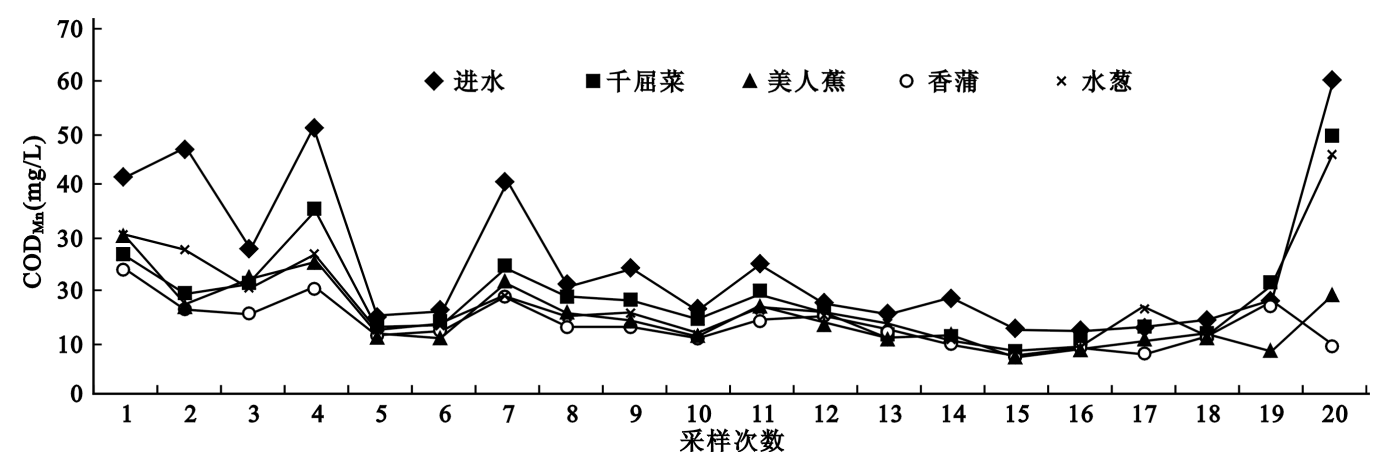

图 2 表面流人工湿地系统进出水 $\mathrm{COD}_{\mathrm{Mn}}$ 浓度

Fig. $2 \mathrm{COD}_{\mathrm{Mn}}$ Concentration of influent and effluent of SFW systems

从图 2 可以看出, 不同植物的表面流人工湿地系统出水 $\mathrm{COD}_{\mathrm{Mn}}$ 浓度曲线基本与进水保持一致趋势, 去 除效率相对稳定. 图中出现少数出水 $\mathrm{COD}_{\mathrm{Mn}}$ 浓度高于进水的现象, 究其原因, 是因为取样当天进水 $\mathrm{COD}_{\mathrm{Mn}}$ 浓度特别低,前一天吸附在植物和土壤表层的有机质随水流重新释放进人水体的结果.

\section{2 系统对 $\mathrm{NH}_{4}^{+}-\mathrm{N}$ 的去除效果}

4 个不同植物的表面流人工湿地系统 $\mathrm{NH}_{4}^{+}-\mathrm{N}$ 的进出水浓度和平均去除效率如表 3,20 次监测结果及 进出水 $\mathrm{NH}_{4}^{+}-\mathrm{N}$ 浓度变化如图 3.

表 2 表面流人工湿地系统试验 $\mathrm{NH}_{4}^{+}-\mathrm{N}$ 监测结果

Tab. 2 Monitoring results of $\mathrm{NH}_{4}^{+}-\mathrm{N}$ of SFW system

\begin{tabular}{|c|c|c|c|c|c|}
\hline \multirow{2}{*}{$\begin{array}{l}\text { 植物 } \\
\text { 类型 }\end{array}$} & \multicolumn{2}{|c|}{ 进水浓度 $(\mathrm{mg} / \mathrm{L})$} & \multicolumn{2}{|c|}{ 出水浓度 $(\mathrm{mg} / \mathrm{L})$} & \multirow{2}{*}{$\begin{array}{c}\text { 平均去除率 } \\
(\%)\end{array}$} \\
\hline & 范围 & 平均浓度 $(\mathrm{mg} / \mathrm{L})$ & 范围 & 平均 & \\
\hline 千屈菜 & & & $0.36-8.88$ & 2.06 & 65.26 \\
\hline 美人蕉 & $1.37-20.18$ & 5.93 & $0.38-3.81$ & 1.75 & 70.49 \\
\hline 香蒲 & & & $0.51-11.04$ & 1.97 & 66.78 \\
\hline 水葱 & & & $0.55-13.17$ & 2.46 & 58.52 \\
\hline
\end{tabular}

表面流人工湿地系统对 $\mathrm{NH}_{4}^{+}-\mathrm{N}$ 的去除机理类似于有机物,整个试验期间进水的 $\mathrm{pH}$ 值为 $6.4-8.0$, 非 常有利于湿地系统对氮的去除 ${ }^{[2,3]}$.

表 3 数据显示, 进水浓度相同时, 美人蕉系统出水 $\mathrm{NH}_{4}^{+}-\mathrm{N}$ 平均浓度最低, 仅为 $1.75 \mathrm{mg} / \mathrm{L}$, 美人蕉和香 蒲系统出水 $\mathrm{NH}_{4}^{+}-\mathrm{N}$ 浓度都达到《地表水环境质量标准》(GB3838-2002) $\mathrm{V}$ 类水标准; 水葱系统出水 $\mathrm{NH}_{4}^{+}$$\mathrm{N}$ 平均浓度最高, 为 $2.46 \mathrm{mg} / \mathrm{L} .4$ 个系统对 $\mathrm{NH}_{4}^{+}-\mathrm{N}$ 的去除效果差别明显, 以平均去除率计, 美人蕉、香蒲和 千屈菜系统都超过 $65 \%$,而水葱系统则低于 $60 \%$.

从图 3 可以看出, 4 个系统的出水 $\mathrm{NH}_{4}^{+}-\mathrm{N}$ 浓度始终保持较低值,不随进水浓度的变化而产生较大波 动, 说明整个表面流湿地系统适合于此进水 $\mathrm{NH}_{4}^{+}-\mathrm{N}$ 负荷范围.

\section{3 行洪对系统的影响}

中试工程经历了 2004 年 7-9 月的行洪期,整个行洪期历经 4 个阶段,最大行洪流量 $2000 \mathrm{~m}^{3} / \mathrm{s}$, 最长历 时 $22 \mathrm{~d}$. 行洪对中试工程带来一定的危害, 主要是泥沙的淤积和水生植物的枯萎、死亡现象.

根据沭阳水文站资料,2004 年新沂河的行洪强度能够代表其正常情况,在此强度下,整个表面流湿地 系统出现了泥沙淤积现象, 平均淤积厚度为 $2 \mathrm{~mm}$. 行洪过后, 稍作清理和平整系统表面之后整个系统即可 正常运行. 


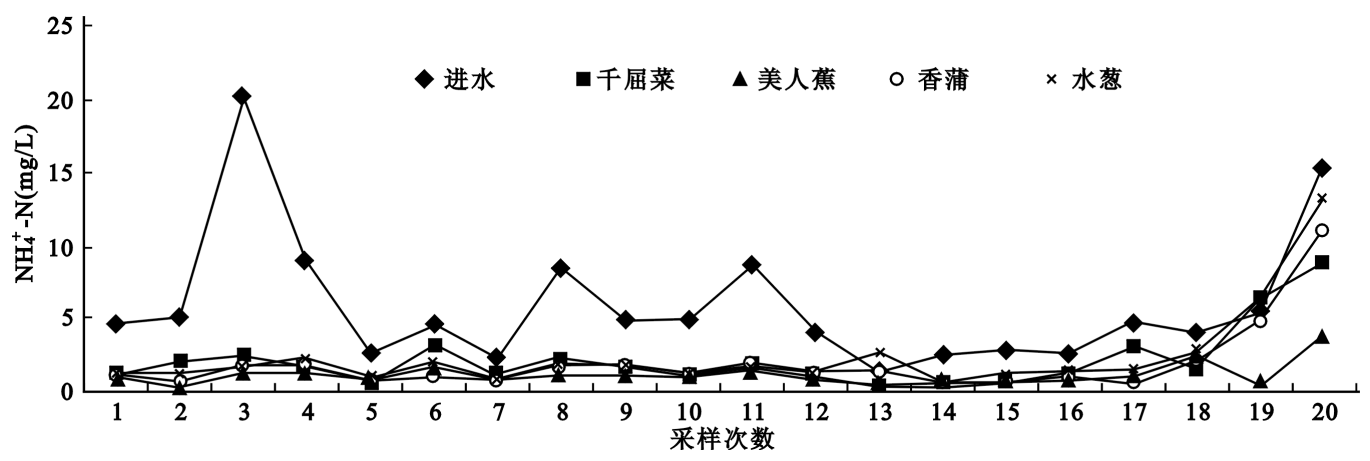

图 3 表面流人工湿地系统进出水 $\mathrm{NH}_{4}^{+}-\mathrm{N}$ 浓度

Fig. $3 \mathrm{NH}_{4}^{+}-\mathrm{N}$ concentration of influent and effluent of SFW systems

行洪在危害系统水生植物生存的同时也考验了植物的耐淹能力, 不同淹水历时下湿地系统植物的生长 状况如表 4.

表 3 不同淹水时间下湿地植物的生长状况

Tab. 3 Vegetation status under different time of overhead flooding

\begin{tabular}{cc}
\hline 完全淹水时间 $(\mathrm{d})$ & 植物生长状况 \\
\hline 7 & 千屈菜地上部分开始枯萎, 根茎存活, 水䓤、香蒲和美人蕉生长良好 \\
10 & 千屈菜地上部分全部枯萎, 根茎存活, 水葱、香蒲和美人蕉生长良好 \\
17 & 千屈菜根茎枯死,香蒲和美人蕉地上部分开始枯黄, 水䓤生长良好 \\
22 & 香蒲和美人蕉地上部分全部枯死, 根茎存活, 水䓤依然生长良好 \\
\hline
\end{tabular}

\section{4 讨论}

污水从表面流人工湿地系统表面流过, 土壤表层水中的微生物充分降解污水中的有机物质. 表层土壤 中的植物根系在与污水接触, 充分吸收污水中营养物质的同时, 也起到了交换、吸附和截留污染物质的作 用. 水生植物对污染物的去除起着重要作用, 除了自身吸收一部分营养物质之外, 还为湿地系统提供大量 的 DO 和为微生物提供栖息地 ${ }^{[4]}$. 湿地系统降解有机污染物和氧化 $\mathrm{NH}_{4}^{+}-\mathrm{N}$ 都要消耗大量的 $\mathrm{DO}^{[5]}, \mathrm{DO}$ 充 足与否将直接影响湿地系统对两者的去除能力.

本中试试验 4 个不同水生植物的表面流人工湿地系统对 $\mathrm{COD}_{\mathrm{Mn}}$ 和 $\mathrm{NH}_{4}^{+}-\mathrm{N}$ 的去除表现出了不同的能 力, 综合比较, 香蒲和美人蕉系统的净化能力较强. 6 月份, 香蒲和美人蕉生长茂密, 表面覆盖率达 $70 \%$ 左 右, 水葱和千屈菜表面覆盖率 $50 \%$ 左右. 香蒲株高 $2.0 \mathrm{~m}$ 左右, 拥有发达粗壮的地下横生根茎, 并伴生有许 多须根, 地下根茎深达 $0.7 \mathrm{~m}$, 分蓝迅速; 美人蕉株高 $1.5 \mathrm{~m}$ 左右, 地下块状根茎粗壮发达, 根系深达 $0.6 \mathrm{~m}$; 水葱株高 $1.5 \mathrm{~m}$ 左右, 茎杆高大通直且中空, 根状茎粗壮匍匐, 伴生有很多须根, 根系深 $0.5 \mathrm{~m}$; 千屈菜株高 $1.0 \mathrm{~m}$ 左右, 地下根茎粗壮, 根系深 $0.5 \mathrm{~m}$, 花期 5-10月, 观赏价值高. 香蒲和美人蕉是土著植物, 当地环境 适合它们生长, 两者植株的繁茂程度、根系的深度和发达程度、对系统的表面覆盖率都高于水葱和千屈菜, 这是香蒲和美人蕉系统净化能力强于水葱和千屈菜系统的主要原因.

泥沙淤积对表面流湿地系统的影响较小, 不会造成垂直流和潜流人工湿地系统经常出现的堵塞现象, 所以在一般行洪强度下, 中试工程只需行洪过后对系统表面稍作清理、平整,整个系统就能够恢复正常运 行. 在类似于新沂河这样的行洪河道, 只要选择耐淹能力强的水生植物, 加强人工管理, 并在行洪过后及时 修复系统, 采用表面流人工湿地系统作为生物 - 生态处置工程是完全可行的. 


\section{3 结论}

(1) 表面流人工湿地系统对污染负荷变化较大的河水中的有机物和 $\mathrm{NH}_{4}^{+}-\mathrm{N}$ 有一定的去除能力, 行洪 淤积对表面流湿地系统影响也较小, 只需选择耐淹能力强的水生植物, 表面流人工湿地系统完全能够运用 于类似区域污染河水的处理;

(2) 在本试验的进水污染物浓度范围内, 千屈菜、水䓤、香蒲和美人蕉都生长旺盛, 说明 4 种植物都适 合于本实验的进水 $\mathrm{COD}_{\mathrm{Mn}}$ 和 $\mathrm{NH}_{4}^{+}-\mathrm{N}$ 负荷范围;

(3) 在本试验的 $\mathrm{COD}_{\mathrm{Mn}}$ 和 $\mathrm{NH}_{4}^{+}-\mathrm{N}$ 进水浓度条件下, 香蒲和美人蕉表面流湿地系统对 $\mathrm{COD}_{\mathrm{Mn}}$ 和 $\mathrm{NH}_{4}^{+}-\mathrm{N}$ 的平均去除效率分别高于 $40 \%$ 和 $60 \%$, 优于千屈菜和水葱系统;

(4) 本试验所选的 4 种水生植物, 水葱耐淹能力最强, 在完全淹水情况下, $22 \mathrm{~d}$ 依然生长旺盛; 千屈菜耐 淹能力最差, 完全淹水 $7 \mathrm{~d}$ 即开始枯萎, $17 \mathrm{~d}$ 死亡; 香蒲和美人蕉完全淹水 $22 \mathrm{~d}$ 地上部分枯死, 根茎存活.

\section{4 参考文献}

１1］国家环境保护局编. 水和废水监测分析方法(第 III 版). 北京: 中国环境科学出版社, 1989.

[2] 郝余祥. 土壤微生物. 北京: 科学出版社, 1982:76-83.

[3] Winogradsky S and Winogradsky H. Nouvelles recherches sur les organisms de la nitrification. Annales de l' Institut Pasteur(Paris), 1933, 50: 350 - 432.

[4] 张 鸿, 陈光荣. 两种人工湿地中氮、磷净化率与细菌分布关系的初步研究. 华中师范大学学报, 1999, 33(4) : $575-578$.

[5] 徐伟锋, 孙力平等. DO 对同步硝化反硝化影响及动力学. 城市环境与城市生态,2003,16(1): 8-10. 